\title{
ANÁLISIS FISICOQUÍMICO Y BIOLÓGICO DEL AGUA PARA CONSUMO HUMANO EN EL DISTRITO DE HUANUARA
}

Responsable: Msc. Edilberto Pablo Mamani Lopez Miembro : Blgo Vicente Chambilla Quispe

\section{RESUMEN}

Las aguas de los ríos de las tres cuencas de la región Tacna, Locumba, Sama y Caplina, presentan diferentes niveles de contaminación natural, especialmente con arsénico, hierro y boro. El presente tema de estudio se refiere a la parte media de la cuenca del río Locumba, en la zona de captación del río Callazas, aguas abajo llamado río Coranchay, distrito de Huanuara, provincia de Candarave y departamento de Tacna. Las aguas de la zona alta de la cuenca no evidencian contaminación natural, es decir, son de buena calidad. Los focos contaminantes se ubican más abajo, incorporando arsénico y boro.

Es evidente que cualquier emanación de aguas en las partes bajas, como son los manantiales (ojo de agua), se deben a las filtraciones desde las partes altas y los análisis confirman el nivel de contaminación en arsénico $(0,5 \mathrm{ppm})$ y boro $(3 \mathrm{ppm})$, en promedio.

\section{ABSTRACT}

The waters of the rivers of three basins of the region Tacna, Grape liquor, Sama and Caplina, present different levels of natural pollution, specially with arsenic, iron and boron. The present topic of study locates in the average part of the basin of the river Grape liquor, in the zone of captation of the river Callazas, downstream so called river Coranchay; Huanuara's district, Candarave's province and Tacna's department.

The waters of the high zone of the basin do not demonstrate natural pollution, that is to say, they are of good quality. The pollutant areas are located down below, incorporating arsenic and boron. It is evident that any emanation of waters in the low parts, since they are the springs (water eye) owe to the filtrations from the high parts and the analyses confirm the level of pollution in arsenic $(0,5 \mathrm{ppm})$ and boron $(3 \mathrm{ppm})$, in average.

\section{INTRODUCCIÓN}

El distrito de Huanuara se ubica en la provincia de Candarave, departamento de Tacna, en su extremo norte, limita con Moquegua y Puno. El poblado se encuentra a 3150 m.s.n.m. Según magnitudes indicadas por un equipo GPS (explorist 600, Handheld GPS, recepteur GPS portable), el poblado se encuentra en: Latitud sur, $17^{\circ} 18^{\prime} 810$ y Longitud oeste, $70^{\circ} 19^{\prime} 335$.

El promedio anual de \% HR para el mes de julio 2007 ha sido igual a $60 \%$. Se estiman los promedios de temperatura máxima igual a 20 ${ }^{\circ} \mathrm{C}$, la mínima de $3{ }^{\circ} \mathrm{C}$. La presión atmosférica en promedio es de unos $545 \mathrm{~mm} \mathrm{Hg}$.

El territorio del distrito de Huanuara limita por el norte con Cairani, por el sur con Quilahuani y Curibaya, por el este con Candarave y por el oeste con llabaya. El pueblo y su campiña se encuentran en la quebrada de Huanuara cuyo curso va de este a oeste. En el límite con llabaya, a unos 1900 m.s.n.m, las filtraciones de agua forman el río Huanuara, de poco caudal, que se une al río Camilaca en el punto denominado Chejaya, circunscripción de llabaya. En la parte superior de la quebrada, a 3900 m.s.n.m, en el límite con
Candarave, no se aprecia agua en la quebrada, pero sí en época de lluvia.

Los puntos extremos y límites de la quebrada distan entre sí unos $20 \mathrm{~km}$, del límite con llabaya al pueblo de Huanuara son algo más de $9 \mathrm{~km}$ y de éste al límite con Candarave cerca de $10 \mathrm{~km}$. La principal actividad es la agrícola, cultivo de alfalfa para la ganadería, vacunos y ovinos; maíz, papas, orégano para la exportación, alcachofas y otros en menor escala.

Tratando de ubicar los orígenes de las aguas que dan vida a los pueblos de la provincia de Candarave, departamento de Tacna, éstas comprenden la cuenca del río Locumba, en la que se distinguen tres zonas. La primera es la zona de cabecera o cuenca alta, entre los más de 5000 y 3900 m.s.n.m, que es la zona altiplánica y cordillerana donde se capta la mayor cantidad de agua y en la que se encuentra la microcuenca de Suches y los bofedales de Huaytire, que forman la subcuenca de Callazas

La segunda es la zona de captación o cuenca media entre los 3900 y 2400 m.s.n.m, que es una zona semihúmeda y en la que se ubican los valles interandinos, donde el río principal presenta un cauce definido y donde se 
desarrollan variadas actividades productivas. La tercera es la zona de cuenca baja desde los 2400 a 500 m.s.n.m, siendo una zona calurosa y que incluye el litoral de la provincia de Jorge Basadre.

Los orígenes de la cuenca del río Locumba están en la cordillera volcánica, en el extremo norte del territorio tacneño. La cuenca tiene un área total de $5879 \mathrm{~km}^{2}$, de la cual $505 \mathrm{~km}^{2}$ corresponden a la cuenca imbrifera que aporta al escurrimiento superficial. Sus nacientes se ubican en tres fuentes. La primera fuente en el nevado Chuquiananta, en los limites con Moquegua, desde cuya vertiente oriental se genera la quebrada de Tacalaya, y por la vertiente del lado sur se genera la quebrada de Borogueña y la quebrada de Cinto.

La segunda fuente se localiza en la cadena volcánica, con una serie de afluentes que descienden para formar el río callazas, destacando en sus nacientes la laguna de Suches. En este sector se distingue la quebrada de Huanuara como una microcuenca independiente del Callazas, pero que es tributaria del río llabaya, y éste, del Locumba.

La tercera fuente se constituye con dos vertientes: la vertiente del nevado Larjanco de la formación Barroso, al este del volcán Yucamane, cuyos deshielos se juntan con las aguas que provienen de los geiser de la quebrada Calientes, tomando el nombre de rio calientes, el mismo que confluye con el río salado, que es la otra vertiente. El Salado con el Callazas ingresan juntos a la laguna de Aricota, de la cual sale por filtraciones el rio Curibaya. Parte de las aguas del río Callazas derivan hacia los distritos de Candarave, Huanuara, Cairani y Quilahuani.

Al río Callazas se le une el río Matazas y continúa aguas abajo recibiendo las aguas del río Larjanco y Caracara y de los manantiales Vallecito, el Tablar, Azufre grande, Azufre chico, antes de llegar a la repartición en la bocatoma de Coranchay. En este punto se dividen las aguas del río Callazas, una parte para los distritos de Candarave, Quilahuani, Cairani y Huanuara y el resto con destino a la laguna de Aricota

Es interesante destacar que la calidad de las aguas hasta antes del tributario del río Callazas, el río Caracara, es buena. Los márgenes de variación de la conductividad eléctrica (CE), del boro y del arsénico son: conductividad eléctrica (CE): 0,06 a 0,38 . boro: 0,25 a $0,56 \mathrm{mg} / \mathrm{L}$. arsénico : 0,010 a 0,036 $\mathrm{mg} / \mathrm{L}$.

Todos los tributarios del río Callazas, entre el rio Caracara y la bocatoma Coranchay, contribuyen con la contaminación natural por boro y arsénico, como se indica:

Conductividad eléctrica (CE) :2,63 a 3,0 $\mathrm{mS} / \mathrm{cm}$ boro : 7,162 a $15,32 \mathrm{mg} / \mathrm{L}$. asénico: 1,20 a $2,57 \mathrm{mg} / \mathrm{L}$

Como resultado del discurso y mezcla de las aguas, la subcuenca Callazas en el punto de la bocatoma del Coranchay, muestra los siguientes valores: conductividad eléctrica (CE) : $0,871 \mathrm{mS} / \mathrm{cm}$. boro : 4,873 $\mathrm{mg} / \mathrm{L}$. arsénico : $0,652 \mathrm{mg} / \mathrm{L}$

El Proyecto Especial Tacna ( PET ), entre sus actividades, ha realizado en los últimos años análisis fisicoquímicos de las aguas del río Coranchay ( 3900 a 4000 m.s.n.m ), que se destinan para el riego de las campiñas de los poblados y anexos de los distritos de Candarave, Quilahuani, Caírani y Huanuara, entre alturas de 3800 a 3100 m.s.n.m; así como para la bebida de la ganadería propia de estos lugares, en especial vacunos y ovinos, con la producción de leche, queso y carnes.

\section{Del Agua para el Cons:mo Humano}

Es en esta zona donde existen algunos manantiales ( $17^{\circ} 18^{\prime} 527$ y $\left.70^{\circ} 19385\right)$, desde dos de los cuales que se encuentran muy cerca uno del otro y frente del pueblo, a unos $700 \mathrm{~m}$ de distancia, se capta el agua para el consumo humano. Se designará con $A$ el ni: anantial más alto que se encuentra a 3324 m.s.n.m. y con B, el manantial que se encuentra a 3310 m.s.n.m y a unos $30 \mathrm{~m}$ uno del otro. De cada punto de captación se ha canalizado el agua $y$ totalmente cubierta se conducen a pozos, desde los cuales se derivan por gravedad y por diferencia de alturas a la población.

El agua del manantial $A$ que en promedio alcanza un caudal de 1,23 litros por segundo se distribuye por un sistema de tuberias a la parte baja de la población. El agua del manantial B proporciona un caudal de 0,64 litros por segundo y se conduce a un reservorio en la parte alta del pueblo (por gravedad y diferencia de alturas), a la altura de 3275 m.s.n.m (altura del manantial B, 3310 m.s.n.m). Los manantiales Ay B, corresponden al PUNTO 1 , en los resultados de los análisis que se dan en los cuadros siguientes.

Dado que el caudal total de $1,87 \mathrm{~L} / \mathrm{s}$ resulta insuficiente para el consumo humano y para satisfacer la necesidad de agua que demandará un pequeño hospital, la autoridad competente ha considerado captar el agua de otro manantial que se encuentra más arriba y a 
la izquierda de los actuales, indicado como PUNTO 2.

Dado la diferencia de alturas entre la cabecera de cuenca del Locumba, subcuenca del Callazas (desde más de 5000 a 3900 m.s.n.m) y la segunda zona que es de captación, como es el poblado y la campiña de Huanuara, que en su punto más bajo, las áreas de regadío con las aguas del CallazasCoranchay, alcanzan unos 2850 m.s.n.m; es de esperar que todas las filtraciones que emanan (manatiales) se originen de las aguas de la parte alta de la cuenca. Se está aseverando que si las aguas de la parte alta están contaminadas de manera natural con arsénico y boro fundamentalmente, las aguas de los manantiales de estas zonas de alguna manera lo estarán.

\section{MATERIALES Y MÉTODOS}

\section{Instrumentos y Equipos:}

Equipo (GPS) para medir la altura sobre el nivel del mar. $\mathrm{pH}$ metro portátil. Conductímetro, $\mathrm{pH}$ metro. Balanza analitica. Agitador magnético. Espectrofotómetro. Incubadora. Estufa. Autoclave

\section{Materiales y reactivos:}

Diversos materiales de vidrio de laboratorio: vasos, probetas, erlenmeyers, pipetas graduadas, etc. Bombilla de succión de tres vías. Reactivos indicados por las Normas Técnicas.

REACTIVOS (Análisis Microbilógicos): Caldo Bilis Lactosa verde Brillante. Agar Mc Conkey.

Pipetas Serológicas. Tubos de Ensayo : 15 x $150 \mathrm{~mm}$. Frascos Muestreadores de Vidrio resistente de $125 \mathrm{~cm}^{3}$, con tapón. Tubos de Fermentación. Probetas. Balones. Asas de Inoculación. Material Común de Laboratorio. Mechero Bunsen.

\section{Métodos fisicoquímicos de análisis de las aguas:}

Se emplearon los procedimientos de las normas técnicas peruanas (NTP) para realizar los análisis de las muestras de agua. NTP 214.007: 1999 AGUA PARA CONSUMO HUMANO. Determinación del color. Método de comparación visual. 2a. Edición.

NTP 214.018: 1999 AGUA PARA CONSUMO HUMANO

Determinación de la dureza. Método volumétrico EDTA, $2^{\text {a }}$ Edición, etc.
NTP 214.008: 1987 AGUA POTABLE. Determinación de arsénico.

\section{RESULTADOS}

Cuadro 01: Resultados de los análisis fisicoquímicos de las aguas para consumo humano del distrito de Huanuara (2007).

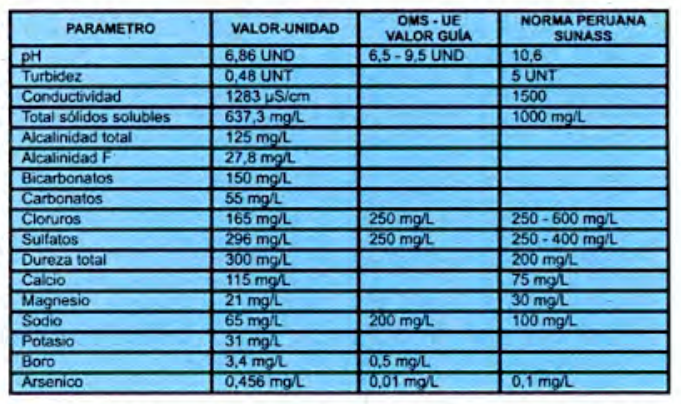

Cuadro 2: Resultados de los análisis microbiológicos.

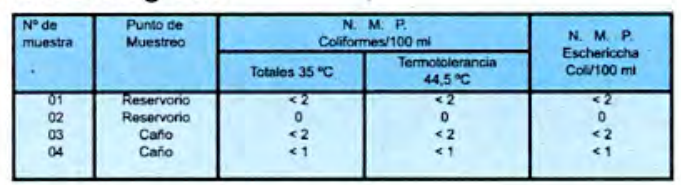

Método de ensayo: método estandarizado de fermentación de tubos múltiples de coniformes totales $\mathrm{y}$ fecales (termotolerantes).

Ley general de aguas, D.L 17752 : Establece que $>2 \mathrm{NMP} / 100 \mathrm{ml}=$ ausencia, tanto para coniformes totales como para coniformes fecales termotolerantes.

\section{DISCUSION}

En el Cuadro $\mathrm{N}^{\circ} 2$ se presenta el resultado que es un promedio entre dos, tres y cuatro mediciones de ciertos parámetros fisicoquímicos. Se aprecia que, en general, el agua natural es de buena calidad, disuelve con gran facilidad el jabón y el detergente, a excepción del alto contenido de arsénico que implica un indicio de contaminación, e igualmente con el boro, por encima de lo establecido por las normas que se mencionan en el Cuadro $\mathrm{N}^{\circ} 1$ del Anexo. Igualmente, los resultados de los análisis microbiológicos no aportan niveles de contaminación.

\section{CONCLUSIONES}

1.Se confirma la contaminación natural por arsénico del agua de consumo humano en el distrito de Huanuara, con una concentración promedio de $0,456 \mathrm{ppm}(\mathrm{mg} / \mathrm{L})$ y en boro con una concentración promedio de 3,4 ppm.

2.Las muestras de agua de red $y$ 
reservorio son aptas para la bebida, ya que presentan bajos indices de coniformes $(<2 / 100 \mathrm{ml})$, y ausencia de microorganismos patógenos.

\section{RECOMENDACIONES}

Realizar analisis del arsenico en las aguas de los diferentes manantiales de la campiña y de otros metales pesados en las aguas de la parte baja.

Realizar el estudio de tratamiento de las aguas para el consumo humano.

Iniciar el estudio global del nivel de contaminacion, como una consecuencia de la disminucion del caudal de las aguas de la mejor calidad de la cuenca del callazas, por mas de 50 años, para atender la demanda de este recurso por la actividades mineras $\left(1.6 \mathrm{~m}^{3} . / \mathrm{s}\right.$ actualmente). relacionar este impacto hacia el futuro en toda la cuenca Locumba.

\section{BIBLIOGRAFIA}

Panty, O. ; Choque, E, y Villegas, E :

Huaytire, visión geohistórica. IESO, Tacna, 2007.

Proyecto Especial Tacna: Calidad de agua Cuenca de Locumba, 2006.

U.S. Environmental Protection Agency; arsenic in drinking water, Drinking Water Standards Development, 2001.
Koneman, Elmer W. y otros:Diagnóstico microbiológico. Edit. Panamericana, Buenos Aires, 3ra. ed. 1996 (Cap. III, págs. 215-255).

Castro, Ma.: Remoción del arsénico en el agua para bebida y biorremediación de suelos; Tercer Seminario Internacional Sobre

Evaluación y Manejo de las Fuentes de Agua de Bebida Contaminada con Arsénico. Universidad de Chile. Santiago, 2004.

Pelksar - Reid - Chan: Microbiología General. edit, McGraw Hill, 2da. ed. 1994 Barcelona, España.

OMS: United Nations Sintesis Report on Arsenic in Drinking Water (Draft), hapetr $\mathrm{N}^{\circ} 6$ : Safe Water Technology Arsénico, http://www.puntoambiental.com/informes/arséni co.pdf- 2006.

EPA: Arsenic Treatment Technology evaluation handbook for small systems; office of water (4606M), EPA 816-R-03-014. Www.epa.gov/safewater.

http://www.digesa.sld.pe/lab dig. http://www.digesa.minsa.gob.pe

Robles M. Digesa, 1995 : Coliformes totales y termotolerantes,determinación del número más probable. Lima.

Frazier, W.c 2003: Microbiología de los alimentos, 4ta edición. Edit. Acribia, Zaragoza, España. 